Revista Científica do Instituto Agronômico, Campinas

\title{
ADUBAÇĀO POTÁSSICA NA PRODUÇÃO DE SOJA, NOS TEORES DE POTÁSSIO NAS FOLHAS E NA DISPONIBILIDADE DE POTÁSSIO EM LATOSSOLO ROXO DISTROFICO DE CERRADO $\left({ }^{1}\right)$
}

hipólito A. A. Mascarenhas (2), Seção de Leguminosas, J. M. A. Da S. Valadares (2), C. L. RotTa $\left({ }^{2}\right)$, Seção de Pedologia, e E. A. Bulisani $\left(^{2}\right)$, Seção de Leguminosas, Instituto Agronômico

\section{RESUMO}

Foram estudadas no período 1973/78, em Latossolo roxo distrófico da Alta Mojiana (SP), as respostas de soja à aplicação de cinco nfveis de adubação potássica, sendo o fertilizante aplicado apenas no primeiro ano. Em nenhuma localidade se observou efeito significativo do potássio na produçāo de sementes de soja nem nos teores desses elementos determinados nas folhas no período de florescimento das plantas em qualquer dos anos estudados. Em vista dessa não-resposta, foram determinados, em 1978, os teores de potássio trocável extraível com $\mathrm{HNO}_{3} 1 \mathrm{~N}$ a quente e do potássio total em amostras dos três latossolos. Pela análise mineralógica da fração grosseira, verificou-se a não-existência de minerais que possam apresentar reservas ponderáveis de potássio. Os baixos teores de potássio trocável e extraível pelo $\mathrm{HNO}_{3}$ a quente $\mathrm{e}$ as boas produçóes de soja obtidas nesses solos mostram que a soja tem grande poder de extração para o potássio do solo e que o nível de $0,12 \mathrm{meq} / 100 \mathrm{~g}$, normalmente apresentado como limite inferior para a disponibilidade do potássio trocável do solo para o caso de soja, em solos de cerrado, e quando se utilizam cultivares de ciclo de 140 dias ou mais, pode ser provavelmente rebaixado para valores ao redor de $0,08 \mathrm{meq} / 100 \mathrm{~g}$ de solo.

\section{INTRODUÇÃO}

O potássio é um nutriente importante para a soja, sendo bem sabido que favorece a retenção das vagens durante sua formação e reduz-lhe a deiscência na maturação, melhora a qualidade das sementes e, em combinação com fósforo e nitrogênio, pode aumentar o conteúdo de óleo das sementes. Também aumenta a resistência da soja ao fungo Diaporthe phaseolorum sojae, que incide principalmente no período de granação e maturação das plantas (9).

CATANI (7), em levantamento dos solos do Estado de São Paulo, mostrou que, em geral, o potássio trocável era baixo. CATANI et alii (8) consideram os teores de $\mathrm{K}$ de 0 a $0,12 \mathrm{meq} / 100 \mathrm{~g}$, como sendo baixos; de 0,12 a $0,30 \mathrm{meq} / 100 \mathrm{~g}$, como mé-

(2) Recebido para publicaçăo a 10 de outubro de 1980.

(2) Com bolsa de suplementação do $\mathrm{CNPq}$. 
dios e os maiores que $0,30 \mathrm{meq} / 100 \mathrm{~g}$, como altos. RAIJ \& MASCARENHAS(16) demonstraram que há resposta de soja para a adubação de $\mathrm{K}$ quando o teor trocável deste no solo é inferior a $0,12 \mathrm{meq} / 100 \mathrm{~g}$, valor acima do qual há pouca ou nenhuma resposta. BOYER (5) apontou que, para agricultura tropical, os níveis mínimos absolutos de potássio trocável estavam ao redor de $0,10 \mathrm{meq} / 100 \mathrm{~g}$, mas variavam de 0,07 a $0,20 \mathrm{meq} /$ $100 \mathrm{~g}$, dependendo do tipo de solo e plantas envolvidas.

MASCARENHAS et alii (10) obtiveram respostas esporádicas à aplicação de potássio em soja, mesmo estando os teores desse elemento no solo abaixo de $0,12 \mathrm{meq} / 100 \mathrm{~g}$ ou 48 ppm utilizando o cultivar Santa-Rosa como planta indicadora. BRAGA et alii (6), no Triângulo Mineiro, empregando o mesmo cultivar, não obtiveram respostas, com soja, à aplicação de potássio em solo com teores desse nutriente considerados baixos. A explicação dada pelos autores foi que o extrator "Carolina do Norte" retira do solo apenas o potássio disponível no momento, mas não aquele que poderia ser liberado durante o ciclo da cultura.

O objetivo deste trabalho foi estudar o efeito imediato e residual da adubação potássica, nos teores de $\mathbf{K}$ das folhas, bem como na produção de soja cultivada em Latossolo Roxo distrófico.

\section{MATERIAL E METODOS}

Foram conduzidos três experimentos, dois no município de Guaíra e um no de Bento Quirino, situados em áreas de Latossolo roxo distróficn recém-desmatado de cerrado. Na pri- meira quinzena de junho/1973, foram aplicados $2.500 \mathrm{~kg} / \mathrm{ha}$ de calcário dolomítico incorporados com enxada rotativa a uma profundidade de aproximadamente $25 \mathrm{~cm}$. Cinco meses depois, instalaram-se os experimentos de adubação com $\mathbf{P}$ e $\mathbf{K}$ em esquema fatorial 5 x 5 , com cinco níveis de fósforo $(0,40,80,120$ e $160 \mathrm{~kg} / \mathrm{ha}$ de $\left.\mathrm{P}_{2} \mathrm{O}_{5}\right)$ e potássio $(0,20,40,60$ e $80 \mathrm{~kg} / \mathrm{ha}$ de $\mathrm{K}_{2} \mathrm{O}$ ) nas formas de superfosfato triplo e de cloreto de potássio respectivamente. Essas aplicações foram efetuadas no sulco, na época de plantio. Cada parcela consistiu em seis linhas de $5 \mathrm{~m}$, espaçadas entre si $0,60 \mathrm{~m}$. Para o cálculo de produção de grãos, consideraram-se somente as duas linhas centrais como área útil, eliminando-se $0,50 \mathrm{~m}$ de cada extremidade. Empregaram-se 25 sementes de soja, cultivar Santa-Rosa, pré-inoculadas por metro de sulco. $\mathrm{Na}$ época do florescimento, foram coletadas amostras das terceiras folhas a partir do ápice das hastes principais das plantas, para serem analisadas quimicamente, conforme descrito por BATAGLIA et alii (2).

Os resultados das análises químicas de solo coletado antes do plantio (1973) encontram-se no quadro 1. Nos anos subsequientes foram estudados os efeitos residuais dessa adubação e, em junho de 1975, foram novamente aplicadas $2,5 \mathrm{t} / \mathrm{ha}$ de calcário dolomítico, para manter no solo $o$ teor de $\mathrm{Ca}^{2+}+\mathrm{Mg}^{2+}$ acima de $3 \mathrm{meq} / 100 \mathrm{~g}$. Em fevereiro de 1978, foram coletadas amostras de solo em profundidades de $0-20,20-40$ e $60-80 \mathrm{~cm}$ nos tratamentos 00 (testemunha absoluta) e 33 (onde foram aplicados $120 \mathrm{~kg} / \mathrm{ha}$ de $\mathrm{P}_{2} \mathrm{O}_{5}$ e $60 \mathrm{~kg} /$ / ha de $\mathrm{K}_{2} \mathrm{O}$ ), nas quais foram determinados os teores de potássio trocável 
(extraído com $\mathrm{HNO}_{3}, 0,05 \mathrm{~N}$ ) e determinado por fotometria de chama, o potássio extraível com $\mathrm{HNO}_{3} 1 \mathrm{~N}$ a quente e potássio total pelo ataque perclórico-fluorídrico $(14,15)$. Para análise mineralógica, tomou-se a fração 0,05 a $0,10 \mathrm{~mm}$ separada por tamisagem. Foram montadas lâminas com líquidos de índice de refração conhecido e contados em média 300 grãos por lâmina. A identificação dos minerais dessa fração de areia foi feita pelos métodos usuais de óptica cristalográfica (4), utilizando-se microscópio polarizador.

\section{RESULTADOS E DISCUSSÃO}

No quadro 2 são apresentadas as médias dos teores de $\mathbf{K}$ nas folhas, bem como as médias das produções de soja nas três localidades. As produções, em todos os níveis de potássio, foram sempre obtidas em presença de fósforo. Os teores adequados de potássio nas folhas situam-se entre 1,7 e 2,5 (12). No primeiro ano (1973/74), a aplicação de potássio no solo não aumentou os teores desse elemento nas folhas, que não ultrapassaram o limite superior da faixa adequada, e também não influenciou a produção. No primeiro ano de efeito residual, os teores de potássio, mesmo sem a aplicação desse nutriente, estiveram além do limite superior da faixa adequada em Guaíra I e II, mas em Bento Quirino mantiveram-se dentro da mesma. Não houve diferenças na produtividade de tratamentos com e sem aplicação de potássio. Esse fato também foi observado no șegundo e no terceiro ano de efeito tesidual, sendo as produções sempre maiores do que as de 1973/74. No terceiro ano, houve uma redução nos teores de potássio nas folhas, espe- cialmente em Bento Quirino, mas sem prejuízo na produção. Esse abaixamento no teor de $\mathrm{K}$ nas folhas das plantas em Bento Quirino pode ser devido ao fato de a amostragem ter sido feita após um período seco, o que afeta a concentração do elemento nas folhas (11). Em 1977/78, foi cultivada a soja pela quarta vez nas três localidades, para estudo do efeito residual, mas, devido a um veranico durante fevereiro, as produções foram prejudicadas.

Conforme BLACK (3), a planta tem capacidade de extrair ou reduzir rapidamente o $\mathrm{K}$ trocável, e se este for insuficiente para sua necessidade, ela vai continuar absorvendo $K$, que passa do estado de lentamente trocável para prontamente disponível. Esse equilíbrio entre essas duas formas é lento e será tanto mais lento quanto mais se esgotar a forma facilmente disponível. Haveria com tempo (bem mais longo), uma lenta passagem do $\mathrm{K}$ da forma pouco solúvel para a mais solúvel. No quadro 3 , em Bento Quirino, tanto no tratamento 00 como no 33 , nos primeiros $20 \mathrm{~cm}$, a quantidade de potássio facilmente trocável é $0,04 \mathrm{meq} / 100 \mathrm{~g}$, insuficiente para suprir as necessidades das plantas de soja; assim, logicamente, elas devem ter extraído o potássio da reserva, que é o $\mathrm{K}$ dificilmente trocável $(0,08$ $\mathrm{meq} / 100 \mathrm{~g}$ extraído na análise com $\mathrm{HNO}_{3} 1 \mathrm{~N}$ a quente), e que é bem maior que trocável $(0,08 \mathrm{meq} / 100 \mathrm{~g})$. $E$ por isso que MASCARENHAS et alii (10) em São Paulo, assim como BRAGA et alii (6) em Minas, não obtiveram respostas à adubação potássica, apesar de os teores trocáveis serem baixos no solo. $O$ mesmo pode ser dito para Guaíra I e II. Deve-se considerar ainda que esses solos são 


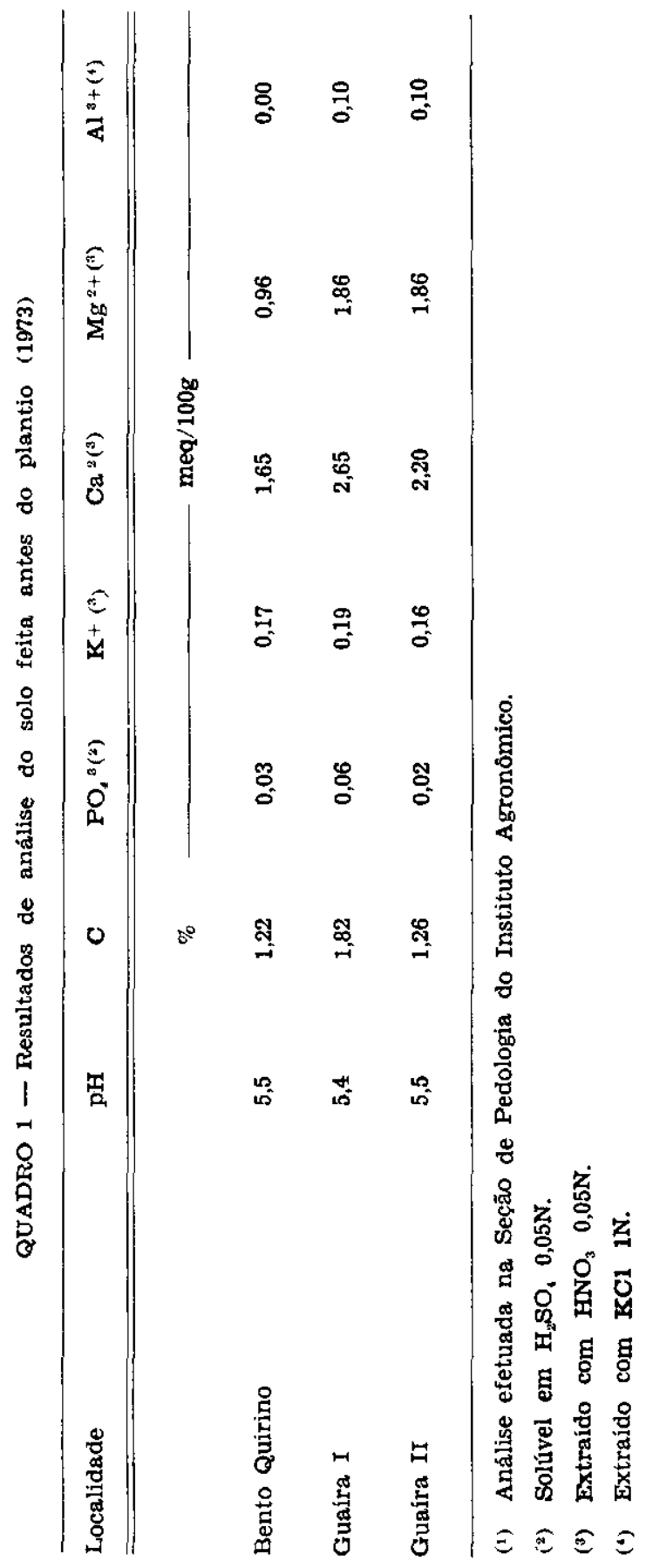


路

政

岂

⿷

瓷

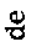

8

急

ฐ

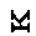

تั

峞

\%

.

1

in

的

영

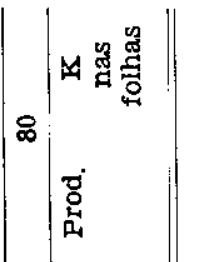

ஃ

$\stackrel{95}{80}$

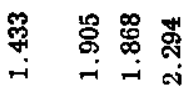

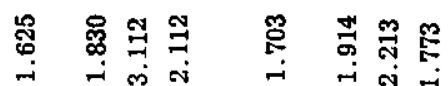

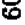

氶 总

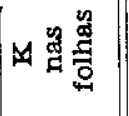

so

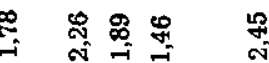

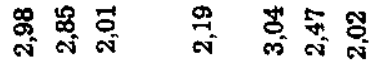

迎

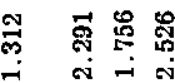

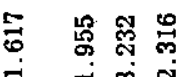

突 둠 声

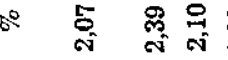

와

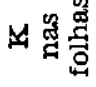

宫

8

劳

จ

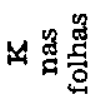

요

\& 역 용

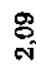

苍点

욕 品

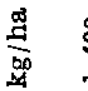

亲芯哭

藏 兽突孚

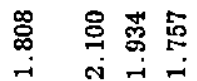

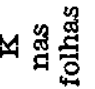

$\circ$

రृ

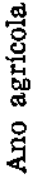

$\therefore$

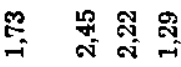

苍 今

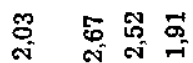

近

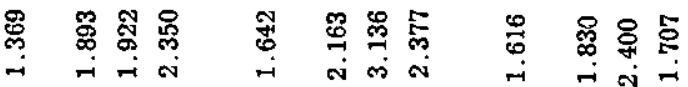

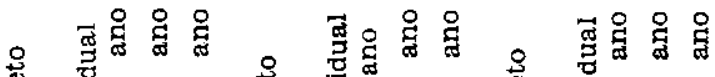

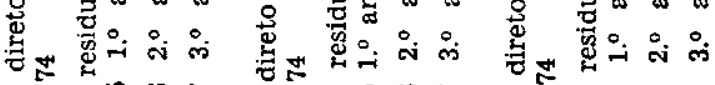

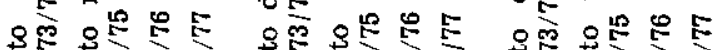

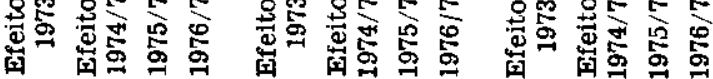
올

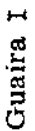




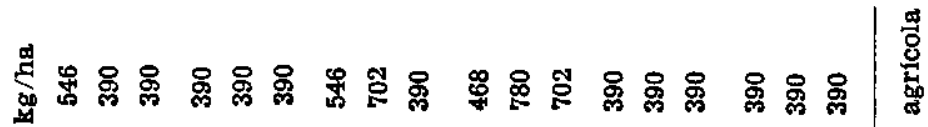
8ొ

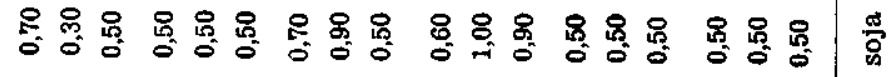
घ्घ

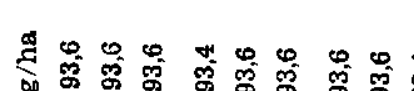

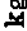

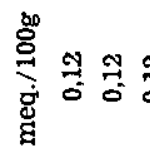

ีํำ 긍 궁

긍 궁 :

ㄱํㅇ 궝 :

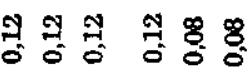

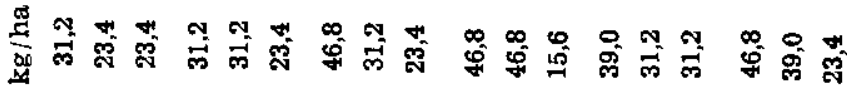

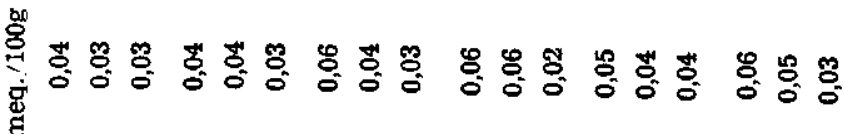

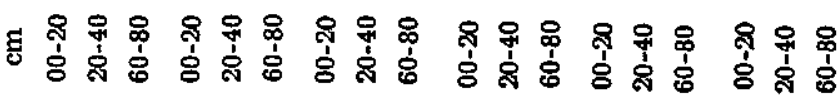
घ

ణ

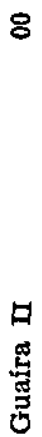

๓ 
pobres em minerais que possam ser fontes de potássio para as plantas, conforme apontado no quadro 4 .

$\mathrm{O}$ ideal seria manter $\mathrm{O} \mathrm{K}$ extraído pelo $\mathrm{HNO}_{3} 1 \mathrm{~N}$ a quente bem acima do nível $0,12 \mathrm{meq} / 100 \mathrm{~g}$ e em quantidade suficientemente grande, para que, no fim do ciclo da planta, ele volte a esse nível, ou apenas um pouco abaixo dele. Pelos valores do quadro 3, verifica-se que o valor "crítico" está ao redor de $0,12 \mathrm{meq} /$ $100 \mathrm{~g}$ para o $\mathrm{K}$ dificilmente trocável mais o trocável. Provavelmente, deveria manter-se o teor de potássio facilmente trocável ao redor de 0,08 meq $/ 100 \mathrm{~g}$. Nas três localidades, principalmente no tratamento sem adubo (00), a extração acumulada de potássio pela soja foi sempre superior à quantidade de potássio trocável inicial menos o potássio trocável que restou no final do ciclo (Quadro 5). Em Bento Quirino, Guaíra I e Guaíra II, a soja utilizou todo o potássio trocável inicial e mais 39,62 e $44 \%$ res- pectivamente do potássio que passou da forma dificilmente trocável para a facilmente trocável. Deve-se considerar também que uma parte do potássio total pode ter sido utilizado através do equilíbrio natural anteriormente descrito. No tratamento adubado, o potássio extraído pela soja veio praticamente todo da forma facilmente disponível mais o adicionado pelo fertilizante.

E sabido que a soja tem alta capacidade para retirar potássio do solo (13). Se considerarmos a forma $\mathbf{K}$ trocável mais $\mathbf{K}$ dificilmente trocável, talvez o nível crítico do $\mathrm{K}$ trocável possa ser reduzido a um valor menor que $0,12 \mathrm{meq} / 100 \mathrm{~g}$ de solo, principalmente em solos de cerrado e quando se usam cultivares de soja de ciclo semitardio e tardio (140 dias ou mais), o que vem confirmar as observações de BOYER (5) e de RITCHEY (17). Novos experimentos estão sendo conduzidos visando a confirmar esses dados.

QUADRO 4. - Fração de areia $(0,05-0,10 \mathrm{~mm})$ de amostras do solo das três localidades do tratamento 00

Localidade

Profundidade Qz. Op.

Fel.

Zr. Tu.

Mi.

$\mathrm{cm}$

Bento Quirino

$0-20$

70

30

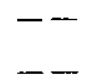

tr.

$\operatorname{tr}$

tr. tr.

Guaíra I

$20-40$

75

25

tr.

tr. tr.

tr.

60

40

tr.

tr.

tr.

Guaíra II

$$
\text { 0-20 }
$$

55

45

tr.

tr.

tr.

tr.

tr.

20-40

55

45

tr.

tr. tr.

tr.

$\mathrm{Qz}=$ quartzo; Op = opaco; Fel = feldspato; $\mathrm{Zr}=$ Zircão; $\mathrm{Tu}=$ turmalina

$\mathrm{Mi}=$ mica; $\mathrm{Tr} .=$ traços. 


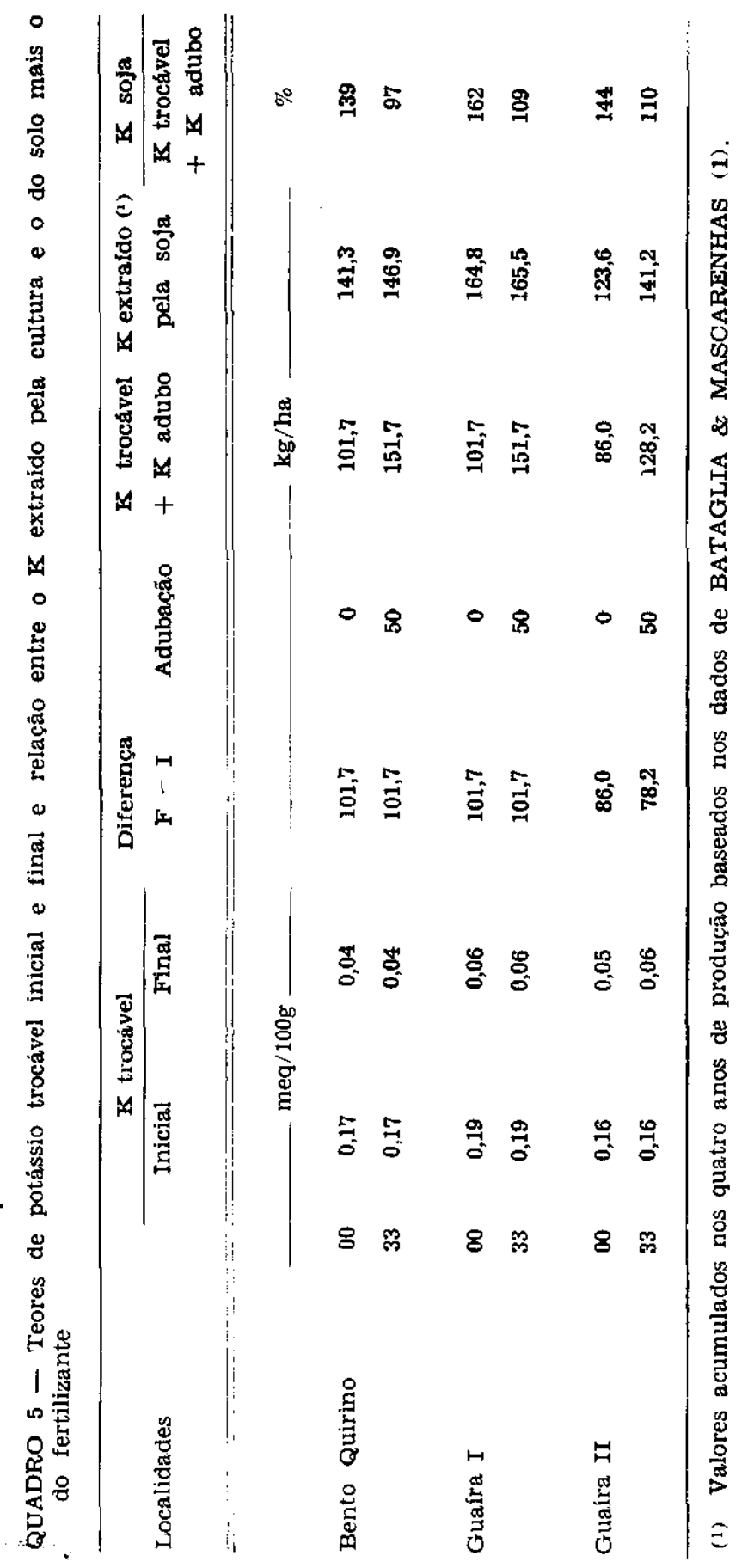


EFFECT OF POTASSIUM FERTILIZATION, ITS AVAILABILITY IN THE CERRADO SOIL, LEAF CONCENTRATION AND YIELD OF SOYBEANS

\section{SUMMARY}

A study was carried out in the North of the State of Sāo Paulo during a five year period $(1973 / 78)$ in the cerrado soil at three localities to study yields of soybeans with the application of different levels of potassium. The potassium in the form of potassium chloride was applied in the rows at planting time only in the first year and in subsequent years only residual effect was studied. At the three localities no significant increase in yield of soybeans was observed nor were there differences in concentration of $\mathbf{K}$ in leaves in any of the years. Chemical analysis were made to determine exchangeable $\mathbf{K}$, nonexchangeable $\mathbf{K}$ with could be released and total soil $K$. The soil mineralogical analysis showed the nonexistance of potassium reserves. Low exchangeable $\mathbf{K}$ and nonexchangeable $\mathbf{K}$ and good yields of soybeans indicated that soybeans have great capacity to extract potassium from the soil and the critical level usually established at 0.12 meq $/ 100 \mathrm{~g}$ in the soil for soybean crop could probably be lowered to approximately $0.08 \mathrm{meq} / 100 \mathrm{~g}$ in cerrado soil for cultivars with 140 or more days maturity.

\section{REFERENCIAS BIBLIOGRAFICAS}

1. Bataglia, O. C. \& MAscarenhas, H. A. A. Absorçāo de nutrientes pela soja. Campinas, Instituto Agronômico, 1977. 36p. (Boletim técnico, 41)

2. - TEIXEIRA, J. P. F.; FURLANI, P. R.; FURLANI, A. M. C.; GaLLO, J. R. Análise química de plantas. Campinas, Instituto Agronômico, 1978. 31p. (Circular, 87)

3. BLACK, C. A. Soil-plant relationships. New York, John Willey, 1968. 675p.

4. BLOSS, F. D. An introduction to the methods of optical-crystallography. Southern Illinois University, U.S.A., 1961. 294p.

5. BOYER, J. Soil potassium. In: Soils of the humid tropics. Washington, Natl. Acad. Sci., 1972. p.102-135.

6. BRAGA, J. M.; FERRARI, R. A. R.; SEDIYAMA, C.; OLIVEIRA, I. M. Respostas de cultivar de soja Santa Rosa à aplicação de $\mathrm{P}, \mathrm{K}$ e calcário em latossolo do Triangulo Mineiro. II - Correlaçăo com análise química do solo. In: CONGRESSO BRASTLEIPO DE CIENCIA DO SOLO, 15., Campinas, 1975. Anais. São Paulo, Soc. Bras. de Ciência do Solo, 1976. p.289-293.

7. CATANI, R. A. Estudos do potássio nos solos do Estado de sāo Paulo. Extratos de tese de concurso para provimento efetivo da $10 .^{\text {a }}$ Cadeira de Química Analítica. Piracicaba, ESALQ, 1955. 39p.

B. ——; Gallo, J. R.; GaRGaNTINI, R. Amostragem do solo, métodos de análise, interpretação e indicaçôes gerais para fim de fertilidade. Campinas, Instituto Agronômico, 1955. 28p. (Boletim, 69)

9. MASCARENHAS, H. A. A.; MIRANDA, M. A. C.; BATAGLIA, O. C.; TISELLI FILHO, O.; BRAGA, N. R.; SOAVE, J. Efeito da adubação potássica sobre o ataque da soja pelo Diaporthe phaseolorum (Cke \& E11) Sacc, Var. sojae (Lehman) Wekm. Summa Phytopathologica, 2:228-234, 1976.

10. - MIYASAKA, S.; BRAGA, N. R.; MIRANDA, M. A. C.; TISSELlI FILHO, O. Calagem e adubação de soja. In: Soja no Brasil Central. Campinas, Fundaçāo Cargill, 1977. p.87-135.

11. NAGAI, V.; IGUE, T.; HIROCE, R. Estudo comparativo das relações entre nutrientes dosados em folhas de café, citros e milho. Bragantia, Campinas, 34:XXIII-XXVIII, 1975. Nota, 6. 
12. OHLROGGE, A. J. \& KAMPRATH, E. J. Fertilizer use in soybeans. In: DINAUER, R. C., ed. Changing patterns in fertilizer use. Madison, Soil Sclence Society of America, 1968. p.237-295.

13. PESEK, J. Potassium nutrition of soybeans and corn. In: KILMER, V. J.; YOUNTS, S.; BRADY, N. C., eds. The role of potassium in agriculture. Madison, Wis., American Society of Agronomy, 1968. p.447-468.

14. PRATT, P. F. Digestion with hydrofluoric and percloric acids for total potassium and sodium. In: BLACK, C. A., ed. Methods of soil analysis. Madison, Wis., American Society of Agronomy, 1965. p.14-21.

15. Potassium. In: BLACK, C. A., ed. Methods of soil analysis. Madison, Wis, American Society of Agronomy, 1965, p.1022-1030.

16. RAIJ. B, van \& MASCARENHAS, H. A. A. Calibração de potássio e fósforo em solos para soja. In: CONGRESSO BRASILEIRO DE CIENCIA DO SOLO, 15. Campinas, 1975. São Paulo, Soc. Bras. Ciência do Solo, 1976. p.309-315.

17. RITCHEY, K. D. Potassium fertility in Oxisols and Ultisols of the humid tropics. Ithaca, 1979. 45p. (Cornell International Agriculture Bulletin, 37) 